\title{
Characterization of Aerosols Containing Microcystin
}

\author{
Yung Sung Cheng ${ }^{1, *}$, Yue Zhou ${ }^{1}$, C. Mitch Irvin ${ }^{1}$, Barbara Kirkpatrick ${ }^{2}$ and \\ Lorraine C. Backer ${ }^{3}$
}

${ }^{1}$ Lovelace Respiratory Research Institute, 2425 Ridgecrest, SE, Albuquerque, NM, 87111, USA; E-mails: yzhou@LRRI.org (for Yue Zhou); cirvin@LRRI.org (C. Mitch Irvin)

${ }^{2}$ Mote Marine Laboratory, 1600 Ken Thompson Parkway, Sarasota, FL 34236, USA; E-mail: bkirkpat@mote.org

${ }^{3}$ National Center for Environmental Health, Centers for Disease Control and Prevention, 4770 Buford Hwy NE, Atlanta, GA, 30341,USA; E-mail: lfb9@cdc.gov

* Author to whom correspondence should be addressed; E-mail: ycheng@LRRI.org; Tel. +1 505-3489410; Fax +1 505-348-8567

Received: 22 September 2007 / Accepted: 10 October 2007 / Published: 12 October 2007

\begin{abstract}
Toxic blooms of cyanobacteria are ubiquitous in both freshwater and brackish water sources throughout the world. One class of cyanobacterial toxins, called microcystins, is cyclic peptides. In addition to ingestion and dermal, inhalation is a likely route of human exposure. A significant increase in reporting of minor symptoms, particularly respiratory symptoms was associated with exposure to higher levels of cyanobacteria during recreational activities. Algae cells, bacteria, and waterborne toxins can be aerosolized by a bubble-bursting process with a wind-driven white-capped wave mechanism. The purposes of this study were to: evaluate sampling and analysis techniques for microcystin aerosol, produce aerosol droplets containing microcystin in the laboratory, and deploy the sampling instruments in field studies. A high-volume impactor and an IOM filter sampler were tried first in the laboratory to collect droplets containing microcystins. Samples were extracted and analyzed for microcystin using an ELISA method. The laboratory study showed that cyanotoxins in water could be transferred to air via a bubblebursting process. The droplets containing microcystins showed a bimodal size distribution with the mass median aerodynamic diameter (MMAD) of 1.4 and $27.8 \mu \mathrm{m}$. The sampling and analysis methods were successfully used in a pilot field study to measure microcystin aerosol in situ.
\end{abstract}


Keywords: Blue-green algae, microcystin, aerosol, inhalation, exposure assessment, cyanobacteria

\section{Introduction}

Cyanobacteria (blue-green algae) are ubiquitous in freshwater lakes, reservoirs, and brackish waters throughout the world (Carmichael, 1992; Oberholster et al. 2004). Under favorable conditions, certain cyanobacteria can form nuisance blooms or scums. Increased source water nutrient enrichment, or eutrophication, may contribute to the blue-green algae blooms (Chorus et al., 2000). These blooms can cause significant environmental impact due to decreased oxygen in the water, resulting in the die-off of fish and other organisms. Similar to marine algal blooms, some blue-green algal blooms can produce a spectrum of natural toxins, including hepatotoxins, neurotoxins, and dermatoxins (Codd et al., 1999). Toxic cyanobacteria blooms can cause acute poisoning to humans and animals.

In the reported incidents of cyanobacteria poisoning in humans and livestock, microcystin is the most frequently cited cyanotoxin. Microcystins, which have several structural variants or congeners, are cyclic toxic peptides. Among approximately 65 variants of microcystin, the most common variant is microcystin-LR (MCYST-LR). These toxins can inhibit liver function and serine/threonine protein phosphatase enzymes. A survey of ponds and reservoirs found microcystin levels between 0.1 to 1000 $\mu \mathrm{g} / \mathrm{L}$ (Welker et al., 2005; Conti et al., 2005). Surface freshwater is being used as the primary source of drinking water for most of the world's population, and the drinking water industry must remove contaminants before providing potable water to people. Public health agencies have proposed guidelines for safe levels of microcystin in water. The World Health Organization's (WHO's) recommended guidelines for drinking water limits the amount of microcystin to1 $\mu \mathrm{g} / \mathrm{L}$ (WHO, 1998).

A further component in the risk assessment of microcystin includes the evaluation of potential routes of exposure. In addition to ingestion and dermal, inhalation is included as a likely route of human exposure (Codd et al., 1999). Respiratory illness, including pneumonia, was reported in a number of people canoeing in freshwater reservoirs containing Microcystis blooms in the United Kingdom (Turner et al., 1990). Several epidemiological studies of human exposure to microcystins during recreational activities in fresh waters have been reported (Philipp et al., 1992; Pilotto et al., 1997; Stewart et al., 2006). Reported health risks among people dinghy sailing in rivers with above normal levels of blue-green algae included minor morbidities such as upper respiratory and gastrointestinal symptoms as well as skin rash, ear pain, and eye irritation (Philipp et al., 1992). A prospective cohort study was conducted to investigate the incidence of self-reported symptoms in individuals exposed, through recreational activity, to cyanobacteria in lakes and rivers in Australia and the United States (Stewart et al., 2006). A significant increase in reporting minor symptoms, particularly respiratory symptoms, was associated with exposure to higher levels of cyanobacteria. A recommended limit ranging from 10 to $400 \mu \mathrm{g} / \mathrm{L}$ of microcystin has been suggested for the safe practice in managing recreational waters (Chorus et al., 1999). A corresponding group of potential health risks have been identified across this range of potential short-term exposure. 
Although aerosols are a potentially important source of exposure to blue-green algal toxins, increased respiratory symptoms are a major health risk when such exposure occurs. None of the anecdotal reports or epidemiological studies of exposure to cyanobacteria during recreational activities have indicated that air samples were taken to ascertain whether cyanotoxins can be airborne and cause these respiratory symptoms. Airborne algae cells, particularly blue-green algae at levels sometimes higher than pollens, were measured in several studies by McGovern et al. (1965) and Mittal et al. (1979). They also reported that many patients with nasobronchial allergies showed reactions to extracts of blue-green algae in skin tests. In addition, Bernstein and Safferman (1966) showed reduction of peak flow in skin-sensitized patients who were challenged with aerosols of green algae extracts.

Algae cells, bacteria, and waterborne toxins can be aerosolized by a bubble-bursting process with a wind-driven white-capped wave mechanism (Blanchard and Syzdek 1972). When bubbles formed by trapped air rise to the water surface they burst and form jet drops and film drops (Blanchard and Syzdek 1975; Woolf et al., 1987. Algae and other microorganisms, which are concentrated in water surface films/forms, are ejected with and carried into the air by the droplets. This process is responsible for transferring salts, organic material, bacteria, and algae from water into the air (Blanchard and Woodcock 1957). One laboratory study has demonstrated the feasibility of aerosolized algae, including blue-green algae, by this bubble-bursting mechanism (Schlichting, 1974). Similarly, brevetoxins, products of marine algae, have been shown to be aerosolized in the laboratory by the same process (Pierce et al., 1989). Marine aerosols containing brevetoxins have been routinely sampled during red tide blooms in Florida (Pierce et al., 2002; Cheng et al., 2005a).

In response to the need to monitor water sources relative to the proposed WHO drinking water guidelines, a number of techniques have been developed for the detection and quantification of microcystins. The standard for such analysis has been physicochemical methods, including liquid chromatography-mass spectrometry (LC/MS) analysis with accompanying sample preparation methods (Maizels and Budde, 2004). However several immunoassay techniques, including enzyme linked immunosorbent assay (ELISA) techniques have been developed and are commercially available (Chu et al., 1990; Fischer et al., 2001; Metcalf et al., 2001).

Within the context of this background, the purposes of this study were to evaluate sampling and analysis techniques for microcystin aerosol, to produce aerosol droplets containing microcystin in the laboratory, and to deploy the sampling instruments in field studies. A commercially available ELISA kit was used for the detection and quantification of collected aerosolized microcystin. ELISA methods have been successfully applied when evaluating water samples and even human exposures via determining microcystin in human tissues (McDermott et al. 1995; Hilborn et al., 2005). The performance of a commercial ELISA kit was evaluated for sensitivity, reproducibility, and accuracy. The efficiency of extracting spiked microcystin from filter material used in the air sampling equipment was determined. The size distribution of microcystin aerosol generated from the bubble-bursting process was measured. Also included is a brief report on microcystin aerosol measurement in a pilot field study. These evaluations are key elements within the overall objective of assessing the inhalation exposure to microcystin aerosols in recreational or occupational settings. The results of the epidemiologic component of this field study are presented in Backer et al., in this issue. 


\section{Results and Discussion}

\subsection{Filter Extraction Efficiency}

Extraction of known concentrations of MCYST-LR from glass fiber media yielded poor results. Four different concentrations of the microcystin solution were spiked on the glass filters. Spike recovery for all of the concentration levels was higher than the expected values. This may indicate a matrix effect interfering with qualification. However, the extraction efficiency of microcystin from the cellulose filter exhibited greater accuracy in measuring the expected values as shown in Table 1 . The extraction efficiency for microcystin was nearly constant in the range of 0.1 to $5 \mathrm{ng}$ on the filter. The mean extraction efficiency is $89.7 \%$ with a standard deviation (SD) of $11.1 \%$. We proceeded to use cellulose filters for sample substrates for both high-volume and personal samplers.

Table 1. Extraction efficiency for the cellulose filter.

\begin{tabular}{cccc}
\hline $\begin{array}{c}\text { Spike mass } \\
(\mathrm{ng})\end{array}$ & $\begin{array}{c}\text { Remaining } \\
\text { vol. }(\mu \mathrm{L})\end{array}$ & $\begin{array}{c}\text { Extraction mass* } \\
(\mathrm{ng})\end{array}$ & $\begin{array}{c}\text { Extraction efficiency* } \\
(\%)\end{array}$ \\
\cline { 1 - 1 } 5 & 800 & $5.53 \pm 0.76$ & $110.6 \pm 15.2$ \\
2.5 & 800 & $2.04 \pm 0.18$ & $81.6 \pm 7.4$ \\
1 & 800 & $0.83 \pm 0.13$ & $82.6 \pm 12.7$ \\
0.5 & 800 & $0.47 \pm 0.10$ & $93.1 \pm 19.1$ \\
0.25 & 800 & $0.22 \pm 0.08$ & $86.9 \pm 30.5$ \\
0.1 & 800 & $0.08 \pm 0.02$ & $82.8 \pm 19.8$ \\
\hline & & Mean & $\mathbf{8 9 . 7}$ \\
& & SD & $\mathbf{1 1 . 1}$ \\
\hline
\end{tabular}

$*$ mean \pm SD

A standard curve showing the ELISA response with MCYST-LR concentrations of 0.1 to 10000 $\mathrm{ng} / \mathrm{L}$ is shown in Figure 1. Also included in the figure is the response for the reading from the cellulose filter extraction when no MCYST-LR was added to the filter. The limit of detection (LOD) can be determined by the mean response of the minimum level of the standard measured plus three times the standard deviation. From Figure 1, an LOD of $70 \mathrm{ng} / \mathrm{L}$ was determined from the ELISA analysis. Assuming a sampling flow rate of $1.2 \mathrm{~m}^{3} / \mathrm{min}$ and sampling time of $360 \mathrm{~min}$, the LOD for the highvolume impactor stage was $0.0014 \mathrm{ng} / \mathrm{m}^{3}$. The LOD for the high-volume filter sample was 0.0037 $\mathrm{ng} / \mathrm{m}^{3}$. Similarly, the LOD for the personal samplers was $0.090 \mathrm{ng} / \mathrm{m}^{3}$ for a sampling flow rate of 10.6 $\mathrm{L} / \mathrm{min}$ and sampling time of $60 \mathrm{~min}$.

\subsection{Particle Size Distribution and Concentration of Aerosolized Microcystins in the Laboratory}

Figure 2 shows a photo of bubbles generated from the glass dispersing tube with a pore size of 145 to $174 \mu \mathrm{m}$. The bubble size is plotted in Figure 3 and shows a mean bubble size of $808 \mu \mathrm{m}$ and 
geometric standard deviation (GSD) of 1.19. Aerosol was produced in the laboratory using the same dispersion tube and a microcystin water concentration of $100 \mu \mathrm{g} / \mathrm{L}$. This aerosol was collected in the high-volume impactor for $30 \mathrm{~min}$ at a flow rate of $300 \mathrm{~L} / \mathrm{min}$. Figure 4 shows the aerosol size distribution from averaging three filter cuts for each substrate filter. The figure shows a bimodal size distribution with the mass median aerodynamic diameter (MMAD) of 1.4 and $27.8 \mu \mathrm{m}$ and the GSD of 2.5 and 1.3 for the two peaks, respectively. The size distribution was taken from the freshly generated droplets. The droplets may undergo evaporation and sedimentation in the atmosphere and change their size, depending on the age of the droplets.

Figure 1. Standard Curve of ELISA response as a function of MCYST-LR concentration.

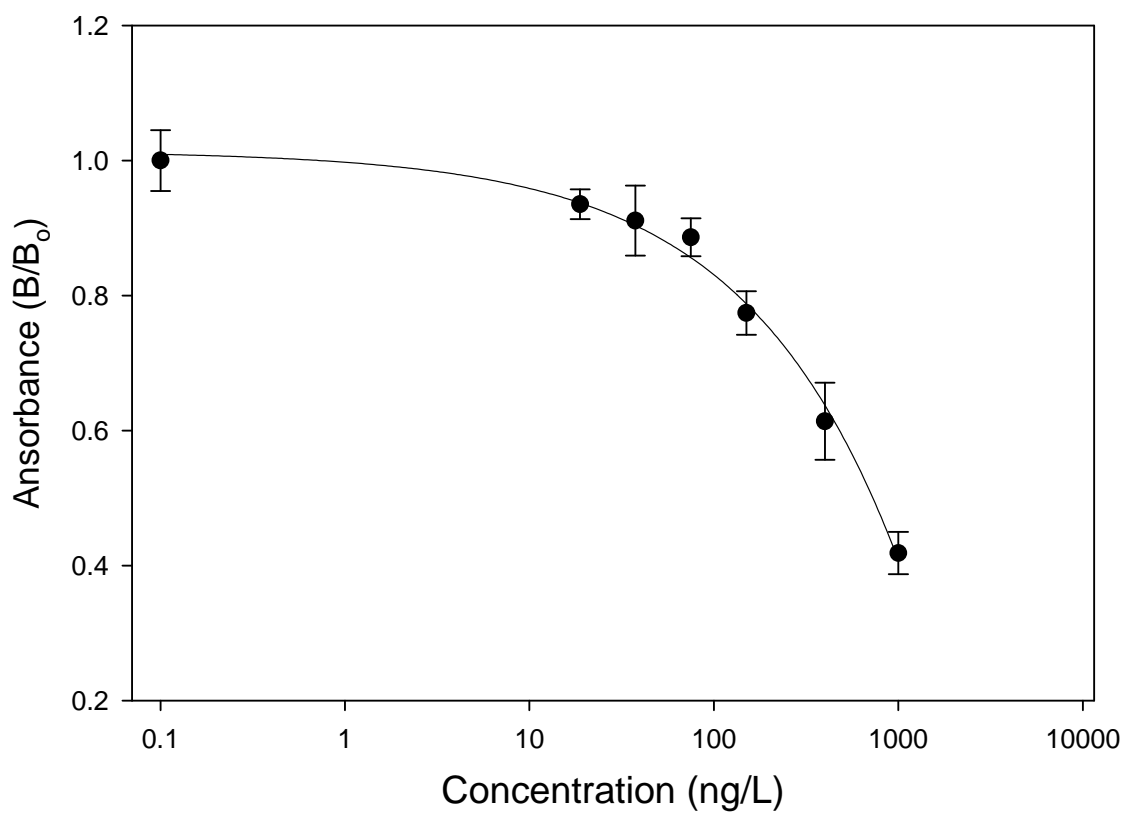

Figure 2. Photo of bubbles produced using a glass dispersion tube.

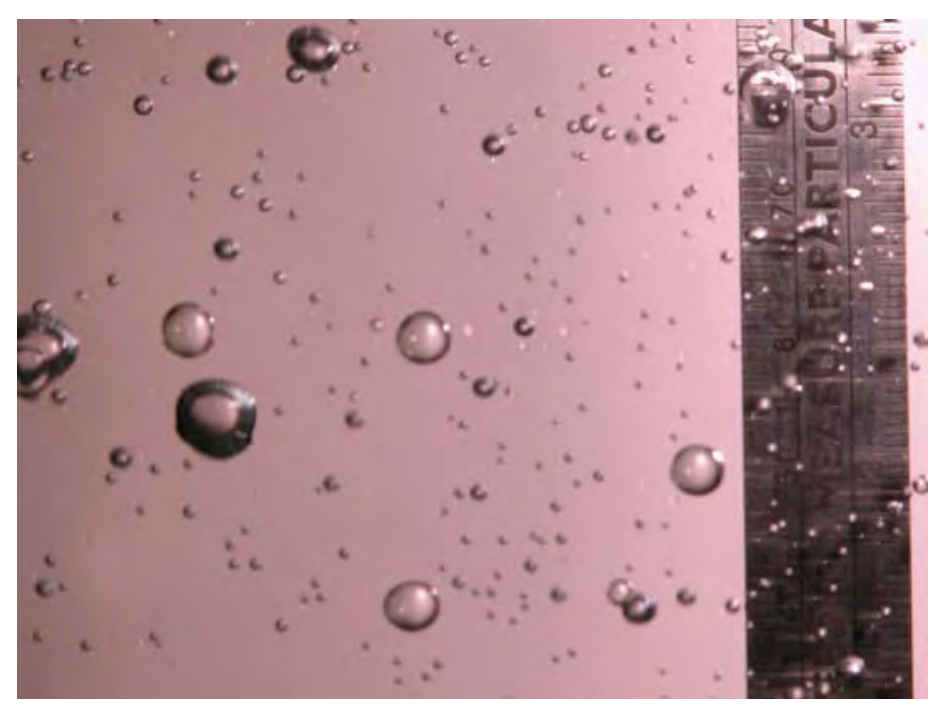


Figure 3. Measured bubble size spectrum generated from a glass dispersion tube.

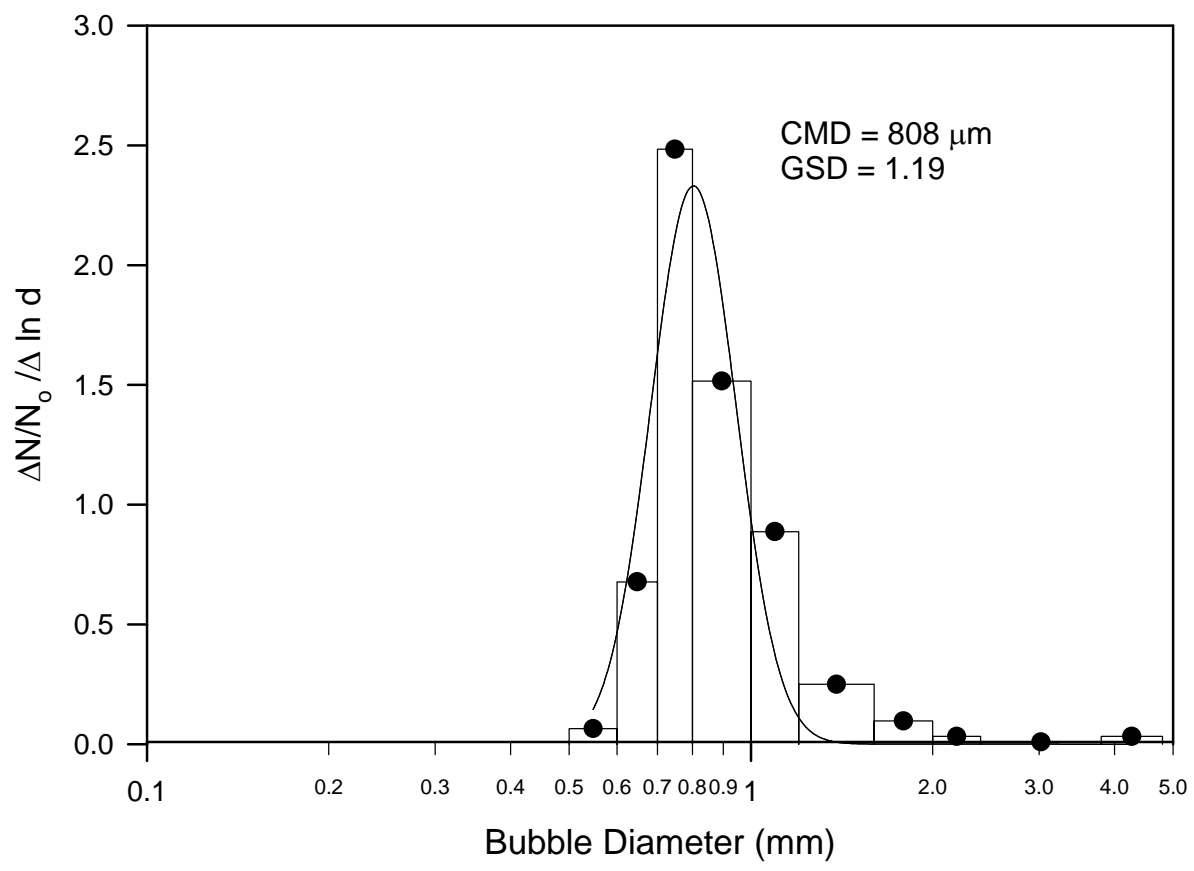

Figure 4. Aerosolized microcystins size distribution measured in the laboratory.

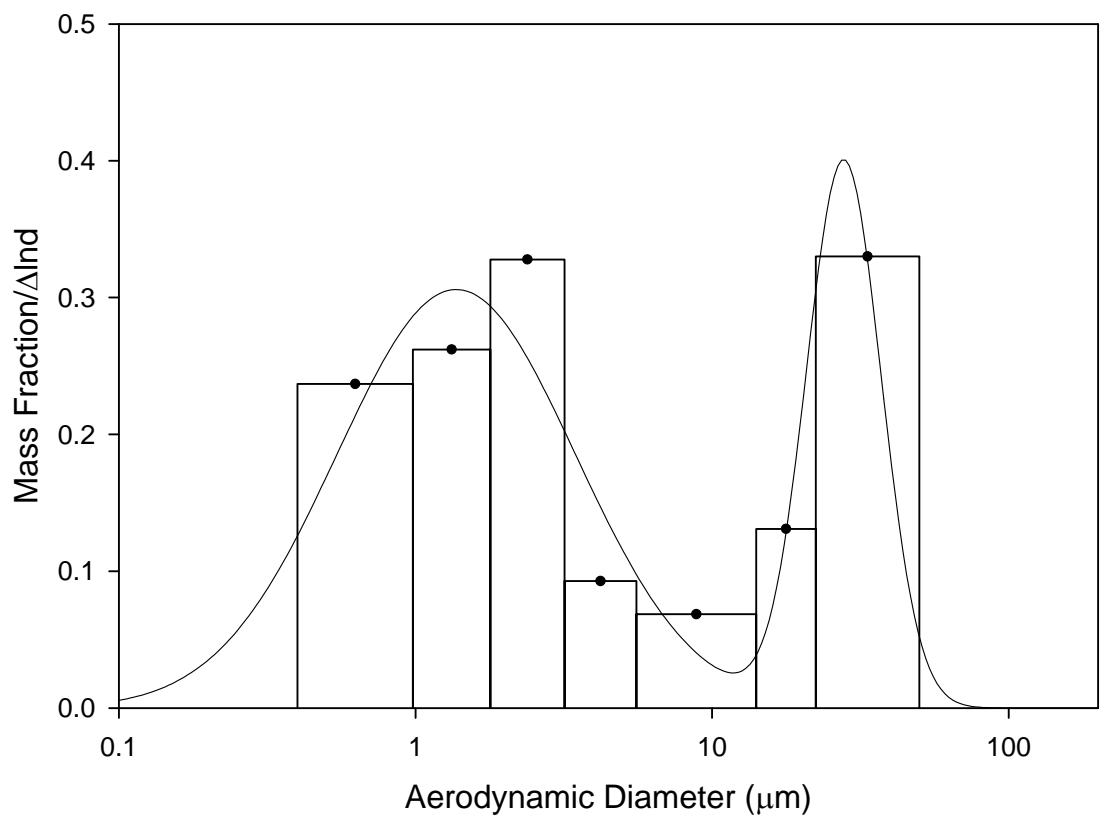

In a separate experiment, aerosol was generated from the same process to determine the microcystin concentration using the IOM personal sampler. The aerosol was generated using an aqueous concentration of $50 \mu \mathrm{g} / \mathrm{L}$ to get air concentrations around the LOD. Four personal samplers were deployed. Two samplers were placed at the center of the chamber while other samplers were at the sides. The aerosol was collected on these personal samplers for $60 \mathrm{~min}$ with a flow rate of $10.6 \mathrm{~L} / \mathrm{min}$. The calculated air concentration, corrected for a mean extraction efficiency of 0.897 , was $0.20 \mathrm{ng} / \mathrm{m}^{3}$ 
and the SD was $0.06 \mathrm{ng} / \mathrm{m}^{3}$. The measured concentration was slightly higher than the LOD (0.09 $\left.\mathrm{ng} / \mathrm{m}^{3}\right)$.

The laboratory study shows that cyanotoxins (including microcystins) in water can be transferred to air via a bubble-bursting process. The size spectrum of the bubbles used in our experimental apparatus was similar to the bubble size spectrum observed from breaking waves in a simulation wave tank (Blanchard and Woodcock 1957; Monahan and Zietlow, 1969). The droplet sizes between 0.1 to 50 $\mu \mathrm{m}$ were similar to what have been measured in the simulated wave tank (Woolf et al., 1987) and likely represent the initial droplet size.

This bubble-bursting process is responsible for the transfer of large quantities of salt, bacteria, algae, and dissolved chemicals from the marine environment to the atmosphere. It is also the process whereby red tide toxins (brevetoxins) generated from marine algae are transferred to the aerosol form. Inhalation of marine red tide aerosol has been found to be the main cause of respiratory symptoms in humans during occupational and recreational exposure (Backer et al., 2005; Fleming et al. 2005). Similarly, inhalation of aerosol containing microcystin may be responsible for respiratory symptoms reported by people participating recreational activities in fresh water containing blue-green algae.

\subsection{Field Study}

The weather conditions during the 8/4/2006 through 8/6/2006 field study are shown in Table 2 . The temperature was relatively stable during the sampling. The average wind speeds were around 3.2 to 3.4 $\mathrm{m} / \mathrm{s}$ on $8 / 4$ and $8 / 6$ but lower $(1.5 \mathrm{~m} / \mathrm{s})$ on $8 / 5$.

Table 2. Weather conditions in Bear Lake during the daytime sampling period.

\begin{tabular}{cccc}
\hline Date & $\begin{array}{c}\text { Temperature } \\
(\mathrm{C})\end{array}$ & $\begin{array}{c}\text { Humidity } \\
(\%)\end{array}$ & $\begin{array}{c}\text { Average Wind Speed } \\
(\mathrm{m} / \mathrm{s})\end{array}$ \\
\hline $8 / 4 / 2006$ & $31.1 \pm 1.4$ & $38.4 \pm 8.4$ & $3.4 \pm 0.9$ \\
$8 / 5 / 2006$ & $29.7 \pm 2.7$ & $46.3 \pm 8.0$ & $1.5 \pm 1.1$ \\
$8 / 6 / 2006$ & $26.0 \pm 2.3$ & $71.7 \pm 10.0$ & $3.2 \pm 1.6$ \\
\hline
\end{tabular}

One high-volume filter and one impactor sample were obtained each day. All three high-volume filter samples showed microcystin levels below the LOD $\left(0.0037 \mathrm{ng} / \mathrm{m}^{3}\right)$. The high-volume impactor samples showed very low but detectable levels of $0.05,0.023$, and $0.057 \mathrm{ng} / \mathrm{m}^{3}$ for $8 / 4,8 / 5$, and $8 / 6$, respectively. Concentration levels at each impactor stage on $8 / 5$ were barely above the LOD. Samples taken on 8/4 and 8/6 were used to determine the particle size distribution as shown in Figure 5A and 5B. Figure 5A shows a bimodal particle size distribution with a fine particle mode at $0.4 \mu \mathrm{m}$ and a coarse particle mode around $6.5 \mu \mathrm{m}$. Figure 5B shows a particle size with a mode around $0.5 \mu \mathrm{m}$ and a lower concentration of coarse particles between 2 to $20 \mu \mathrm{m}$. 
Figure 5. Microcystin particles size distribution obtained in Bear Lake, MI on 8/4/2006 (A) and 8/6/2006 (B).
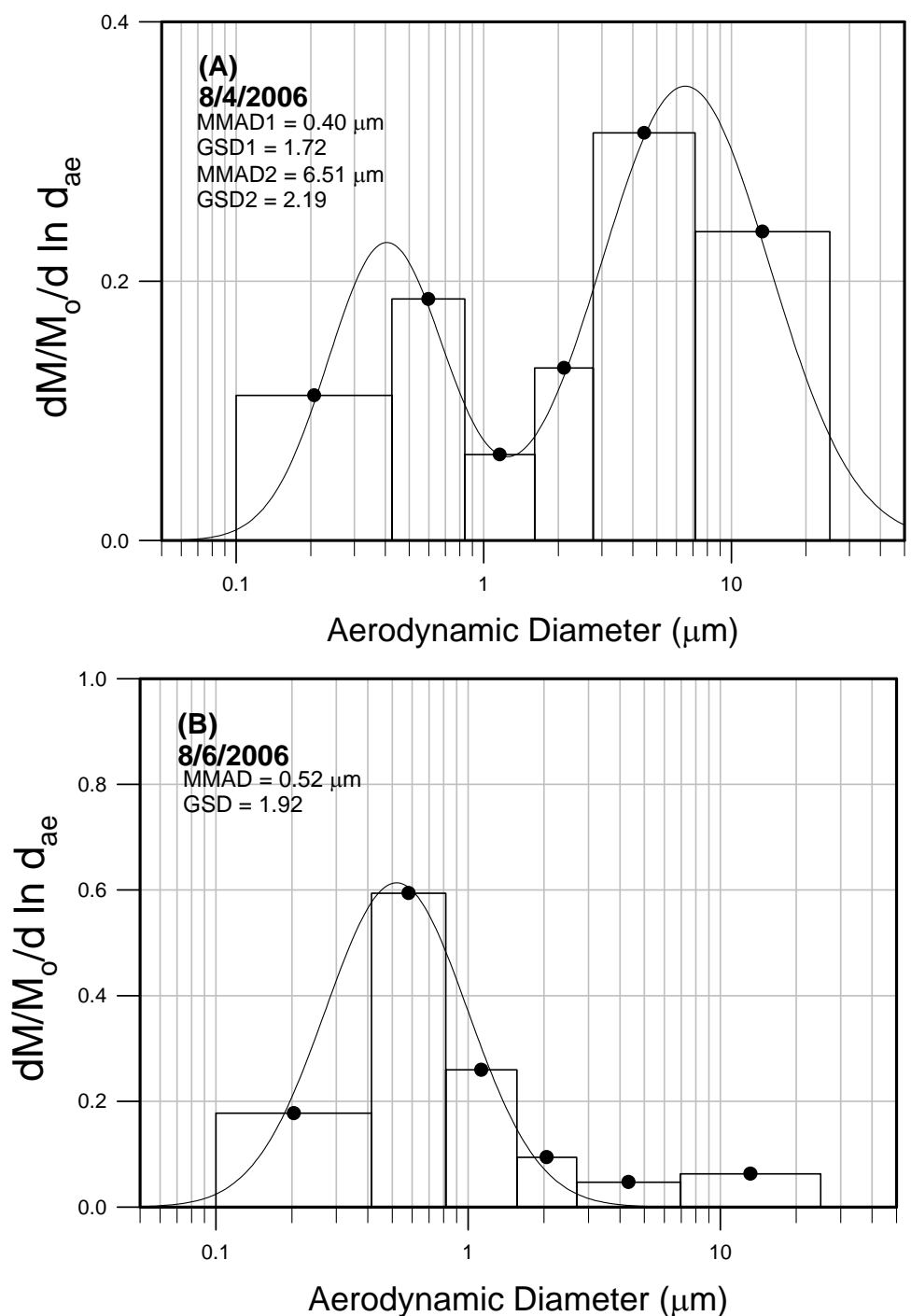

Personal samplers worn by volunteers recreating on the lake were analyzed for microcystin levels. The mean sampling duration varies from 60 to $200 \mathrm{~min}$. One out of 10 personal samples obtained on 8/4 and 4 out of 10 samples obtained on 8/5 were below the LOD. All four samples taken on 8/6 were below the LOD. Table 3 lists the sample number and measured aerosol concentration on 8/4, 8/5, and $8 / 6$.

Table 3. Microcystin concentrations in personal samples.

\begin{tabular}{ccc}
\hline Date & $\begin{array}{c}\text { Microcystin Concentration } \\
\left(\mathrm{ng} / \mathrm{m}^{3}\right)\end{array}$ & Sample Number \\
\hline $8 / 4 / 2006$ & $0.08 \pm 0.09$ & 10 \\
$8 / 5 / 2006$ & $0.07 \pm 0.14$ & 10 \\
$8 / 6 / 2006$ & $0.0 \pm 0.0$ & 4 \\
\hline
\end{tabular}


The particle size distribution in the laboratory experiments showed a bimodal size distribution with a coarse particle mode around 20 to $30 \mu \mathrm{m}$ and a fine particle mode around 1 to $3 \mu \mathrm{m}$. These two size modes may represent the jet drops and film drops, respectively. In the field study we also showed a distinguished bi-modal size distribution for aerosol collected on 8/4. The two size modes were 6.5 and $0.4 \mu \mathrm{m}$, respectively. The size distribution obtained on $8 / 6$ had a similar range but did not show a bimodal distribution.

Assuming the droplets generated in the laboratory represent initial droplets from the bubblebursting process, the particle size distribution may change as the droplets evaporate. The droplet's lifetime is a function of temperature, humidity, and droplet size. For micrometer-sized water droplets the calculated lifetime is less than a second (Hinds, 1999). When a droplet is dried, the particle size is reduced. The final particle size is dependent on the concentration of dissolved material and impurity in the water. This can be calculated as $d_{p}=C^{1 / 3} d_{d}$, where $C$ is the concentration of dissolved material and impurity; and $d_{p}$ and $d_{d}$ are particle diameter and initial droplet diameter, respectively. If we assume the droplet size distribution (Figure 4) was the initial particle size distribution and the concentration of dissolved material and impurity in Bear Lake was $1 \%$, then the final particle size distribution can be calculated and shown in Figure 6. The final particle size also showed two size modes at 6.06 and 0.30 $\mu \mathrm{m}$ respectively, which is in similar size range to the microcystin aerosol (Figure 5A) obtained at Bear Lake. This calculation illustrates a potential aerosol generation process for microcystin aerosol.

Figure 6. Microcystin particle size distributions for impactor samples obtained in Bear Lake, MI on 8/4/2006 (A).

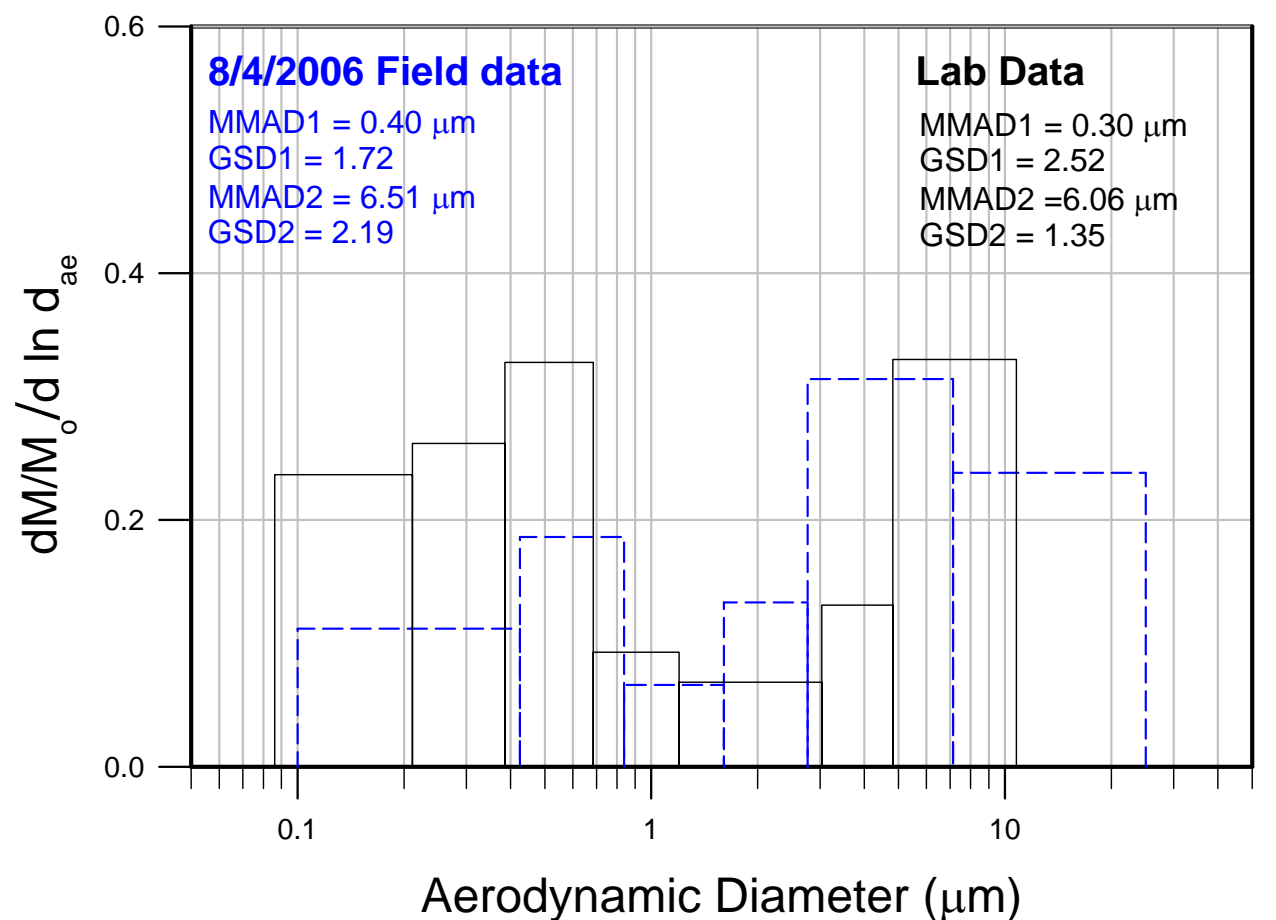




\section{Conclusion}

We developed a sampling technique to obtain airborne microcystins in the laboratory and at a pilot field study. The high-volume samplers collect large volumes of air and thus have a lower LOD whereas the personal samplers have a higher LOD because of low sampling flow rates. The highvolume cascade impactor also provided information on particle size distribution, which is an important parameter in estimating the inhaled dose. The commercial ELISA kits used standards of MCYST-LR for calibration, thus all concentrations were reported in nanograms of MCYST-LR per cubic meter of air. The ELISA analysis did not differentiate the chemical forms of cyanotoxins. Additional techniques such as high-performance liquid chromatography (HPLC) or LC/MS would be needed. The standard curves were slightly different each time when we analyzed our samples using ELISA standards. As recommended by the manufacturer's instructions, a standard curve was determined for each analysis. For each individual standard regression, the $r^{2}$ value varied between 0.94 and 0.99 , indicating some variability. This variability is typical of ELISA analysis and affects its accuracy and precision. For more accurate microcystin analysis, the HPCL or LC/MS method may be required. However, the ELISA technique is acceptable for analyzing microcystin aerosol samples.

Our experiments showed that glass fiber is not an optimal substrate for analyzing microcystin using the ELISA method. Cellulose filters, on the other hand, showed very good extraction efficiency with a mean efficiency near $90 \%$. The SD for the high concentration spike was below $20 \%$ and increased to a maximum of $30 \%$ for the low concentration spike.

The laboratory study shows that cyanotoxin in water can be transferred to air via a bubble-bursting process. The droplets containing microcystins showed a bimodal size distribution with the MMAD of 1.4 and $27.8 \mu \mathrm{m}$.

The techniques were used in a pilot study to determine if aerosols containing microcystin could be found in fresh water with a blue-green algae bloom and if people engaging in recreational activity in the area could be exposed to the aerosol. The preliminary results show positive answers to both questions. Because of low levels of the microcystin (around $1 \mu \mathrm{g} / \mathrm{L}$ ) in the water, the aerosol samples contained very low levels of microcystin barely above the LOD. In fact, over half of the personal samples contained a microcystin concentration below LOD. This field study demonstrated that we can detect very low levels of microcystin aerosol in areas with blue-green algae. Both high-volume and personal samplers show microcystin concentrations between 0.02 to $0.08 \mathrm{ng} / \mathrm{m}^{3}$. This confirmed our laboratory results. In future studies of recreational exposure to blue-green algae blooms, aerosol characterization can provide useful information for determining the exposure and dose of inhaled microcystin.

\section{Materials and Methods}

\subsection{Aerosol Sampling Equipment}

Aerosol sampling equipment used to collect red tide aerosol containing brevetoxins produced by Karenia brevis were used in this study (Cheng et al., 2005a,b,c). High-volume samplers (Model G2000H, Andersen Instruments, Smyrna, GA) were used to collect large quantities of aerosol material 
for identification and quantization of microcystin. These samplers can house filters for collecting the total particulate sample. Alternatively a five-stage, high-volume cascade impactor (Model SA235, Andersen Instruments) can be placed inside the housing of a high-volume sampler. The impactor stage consists of rectangular slot jets. The air moves toward a collecting plate, then the flow makes a 90degree turn to go to the next stage. Particles are accelerated through the jet; particles with aerodynamic diameters larger than a specified cutoff diameter will not be able to follow the air flow because of inertia and will be collected in the plate. Smaller particles can follow the flow to the lower stage. A smaller nozzle size in the lower stages is designed to collect smaller particles. The sampler can be operated at a flow rate between 300 to $1000 \mathrm{~L} / \mathrm{min}$. At $566 \mathrm{~L} \mathrm{~min}^{-1}$, the impactor has $50 \%$ cutoff aerodynamic diameters of 10.2, 4.2, 2.1, 1.4, and $0.73 \mu \mathrm{m}$. Six filter substrates were used to collect the six size-classified samples. Cellulose filters $(15 \mathrm{~cm}$ x $14 \mathrm{~cm}$ ) (Filter Paper 41, Whatman International Ltd., Maidstone, UK) were used as substrates.

Personal exposure levels of human subjects in epidemiological studies were assessed by individuals wearing personal sampler (IOM Inhalable Dust Sampler, SKC Inc., Eighty Four, PA) connected to a battery-operated pump (Leland Legacy pump, SKC Instruments). The sampler was placed at the lapel near the breathing zone. The IOM Inhalable Sampler is designed to collect particles that are hazardous when deposited anywhere in the respiratory tract and follows the definition of inhalable particulate matter (Mark and Vincent, 1986; Phalen et al., 1986). Twenty-five-milliliter cellulose filters or glass filters (Type A/E, Gelman Sciences, Ann Arbor, MI) were tested as the collection substrate. The sampling flow rate of $10.6 \mathrm{~L} \mathrm{~min}^{-1}$ was checked with a DryCal Flow Calibrator (BIOS International, Pompton Plains, NJ).

\subsection{Analysis of Microcystin}

Filter substrates used in the high-volume sampler and personal samplers were extracted for analysis via an ELISA method. ELISA kits for MCYST-LR were purchased from Abraxis (Production \#520011, Abraxis LLC, Warminster, PA). The kits included a microtiter plate coated with an analog of microcystins conjugated to a protein, the standards (0, 150, 400, 1000, 5000 ppt), the antibody solution, the anti-sheep-HRP conjugate, the wash solution, the color solution, and the stop solution. The procedures suggested by the manufacturer were followed.

The extraction efficiency of filter samples was determined as follows. One-hundred microliters of a defined MCYST-LR (CyanoHAB Services, Wright State University, MI) concentration was spiked on either a 25-mm cellulose (Whatman 41, Whatman International Ltd.) or glass-fiber (Whatman EPM2000, Whatman International Ltd.) filter. The extraction efficiency of both filter materials was experimentally determined. The filter was put into a glass vial, and $1 \mathrm{~mL}$ of phosphate buffer solution (PBS) was added. The vial was vortexed (Digital Vortex Mixer, Fisher Scientific, Denver, CO) for 30 $\mathrm{s}$, and placed on a circular rotator (Roto-Torque ${ }^{\circledR}$ Low Speed \#10; Cole-Parmer Instruments, Vernon Hills, IL) for $10 \mathrm{~min}$. After rotation, the filter was removed from the extraction tube and the extract was used for ELISA analysis of microcystin. Before analysis, the final volume of the remaining extraction solution was measured to account for solvent that was absorbed by the filter. 


\subsection{Aerosolization of Microcystin}

Droplets of microcystin were generated in the laboratory using an aqueous solution by bubblebursting process. The experimental apparatus included a glass beaker placed inside a plastic tank as shown in Figure 7. The solution with microcystin concentrations of 50 and $100 \mu \mathrm{g} / \mathrm{L}$ was placed into the beaker. A glass dispersing tube with a pore size of 145 to $174 \mu \mathrm{m}$ was placed in the beaker and connected to the compressed air hose with an airflow rate of $0.2 \mathrm{~L} / \mathrm{min}$ to generate bubbles. The bubbles burst open and droplets were produced as they reached the surface of the solution. A highvolume cascade impactor (Model SA235; Andersen Instruments), was used in this study to measure the aerosol size distribution.

Figure 7. Experimental set-up for aerosolization of microcystin and impactor sampling device.

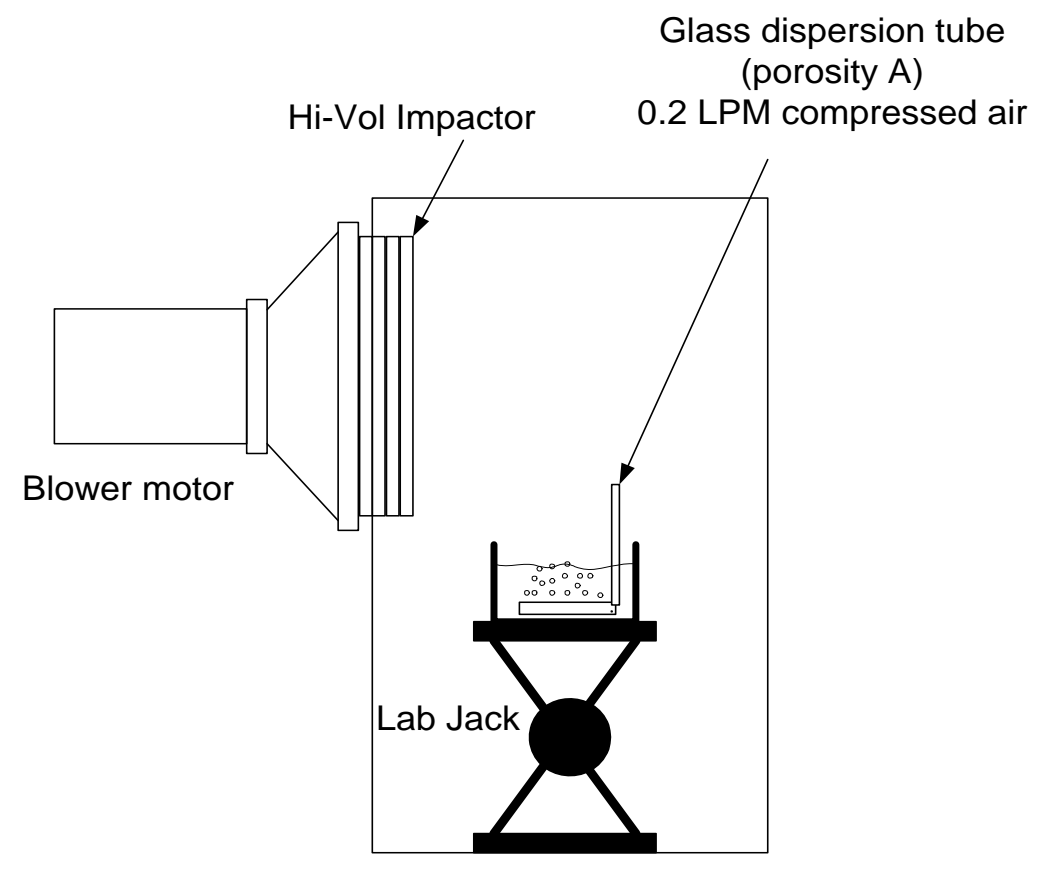

Personal samplers (IOM Inhalable Dust Sampler; SKC, Inc.) were used to determine the minimum concentration of aerosolized waterborne microcystins that could be detected. The sampling flow rates for the high-volume impactor and the personal sampler were $300 \mathrm{~L} / \mathrm{min}$ and $10.6 \mathrm{~L} / \mathrm{min}$, respectively. Water samples were taken before and after the test. Each impactor filter was cut into three small pieces (one from the top, one from the bottom, and one from the middle) for analysis after the test.

\subsection{Field Study}

A pilot field study was conducted to assess the exposure levels of people at risk for swallowing water or inhaling spray during recreational activities (water skiing, jet skiing, and boating) during a Microcystis aeruginosa bloom in a small recreational lake in Michigan on August 4 to August 6, 2006. Detailed experimental design and results were reported by Backer et al. (this issue). Here, we briefly 
describe the aerosol sampling and monitoring of weather conditions. Two high-volume air samplers, each including a filter sample or a cascade impactor (Model SA235; Andersen Instruments), were placed on a motor boat that circulated in the lake to collect aerosol samples in the area. Personal samplers (IOM Inhalable Dust Sampler; SKC, Inc) were worn by human volunteers recreating on the lake to assess personal exposure levels. The sampling flow rates for the high-volume impactor and the personal sampler were $1170 \mathrm{~L} / \mathrm{min}$ and $10.6 \mathrm{~L} / \mathrm{min}$, respectively. Cellulose filters as tested in our laboratory were used as the collection substrates. The high-volume samples were then cut into three pieces of about $12 \mathrm{~cm}^{2}$ for analysis. Larger pieces were needed because of low aerosol concentration.

A portable, solar-powered weather station was deployed on the Bear Lake waterfront near the impactor sampler to provide wind speed and direction, temperature, and relative humidity (Complete Weather Station, Davis Instruments, Hayward, CA). It continued to monitor weather conditions during the sampling period and the data were downloaded daily. The wind direction was measured at Bear Lake in 16 quadrants.

\section{Acknowledgements}

This research was supported by the National Center for Environmental Health, Centers for Diseases Control and Prevention, and the National Institute of Environmental Health Sciences (NIEHS) program project P01-ES10594.

\section{References}

1. Backer, L. C.; Carmichael, W.; Kirkpatrick, B.; Williams, C.; Irvin, M.; Zhou, Y.; Johnson, T.B.; Nierenberg, K.; Hill, V.R.; Kieszak, S.M.; Cheng, Y.S. Recreational exposure to microcystins during a Microcystis aeruginosa bloom in a small lake. Marine Drugs (submitted).

2. Bernstein, I. L.; Safferman, R. S. Sensitivity of skin and bronchial mucosa to green algae. $J$. Allergy 1966, 38, 166-173.

3. Blanchard, D. C.; Syzdek, L. D. Concentration of bacteria from bursting bubbles. J Geophys. 1972, 77, 5087-5099.

4. Blanchard, D. C.; Syzdek, L. D. Electrostatic collection of jet and film drops. Limnol. Oceano. 1975, 20, 762-774.

5. Blanchard, D. C.; Woodcock, A. H. Bubble formation and modification in the sea and its meterological significance. Tellus 1957, 9, 145-158.

6. Carmichael, W. W. Occurrence of toxic cyanobacteria. In A Status Report on Plantonic Cyanobacteria (Blue-Green Algae) and their Toxins, US Environmental Protection Agency: 1992; pp 15-26.

7. Cheng, Y. S.; McDonald, J.; Kracko, D.; Irvin, C. M.; Zhou, Y.; Pierce, R. H.; Bourdelais, A.; Naar, J.; Baden, D. G. Concentrations and particle size of airborne toxic algae (brevetoxin) derived from ocean red tide events. Environ. Sci. Technol. 2005a, 39, 3443-3449.

8. Cheng, Y. S.; Villareal, T. A.; Zhou, Y.; Gao, J.; Pierce, R. H.; Wetzel, D.; Naar, J.; Baden, D. G. Characterization of red tide aerosol on the Texas coast. Harmful Algae 2005b, 4, 87-94. 
9. Cheng, Y. S.; Zhou, Y.; Irvin, C. M.; Pierce, R. H.; Naar, J.; Backer, L. C.; Fleming, L. E.; Kirkpatrick, B.; Baden, D. G. Characterization of marine aerosol for assessment of human exposure to brevetoxins. Environ. Health Perspectives. Environ. Health Perspectives 2005c, 113, 638-643.

10. Chorus, I.; Bartram, J. Toxic cyanobacteria in water. A guide to their public health consequences, monitoring, and management.; E \& FN Sponsored on behalf of the World Health Organization: 1999.

11. Chorus, I.; Falconer, I. R.; Salas, H. J.; Bartram, J. Health risks caused by freshwater cyanobacteria in recreational waters. J. Toxicol. Environ. Health (B) 2000, 3, 323-347.

12. Chu, F.S.; Huang, X.; Wei, R. D. Enzyme-linked immunosorbent assay for microcystins in bluegreen algal blooms. J. Assoc. Off. Anal. Chem. 1990, 73 (3), 451-456.

13. Codd, G. A.; Bell, S. G.; Kaya, K.; Ward, C. J.; Beattie, K. A.; Metcalf, J. S. Cyanobacterial toxins, exposure routes and human health. Eur. J. Phycol. 1999, 34, 405-416.

14. Conti, A. L.; Guerrero, J. M.; Regueira, J. M. Levels of microcystins in two Argentinean reservoirs used for water supply and recreation: differences in the implementation of safe levels. Environ. Toxicol. 2005, 20, 263-269.

15. Fischer, W. J.; Garthwaite, I.; Miles, C. O.; Ross, K. M.; Aggen, J. B.; Chamberlin, A. R.; Towers, N. R.; Dietrich, D. R. Congener-independent immunoassay for microcystins and nodularins. Environ. Sci. Technol. 2001, 35, 4849-4856.

16. Hilborn, E. D.; Carmichael, W. W.; Yuan, M.; Azevedo S.M.F.O A simple colorimetric method to detect biological evidence of human exposure to microcystins. Toxicon 2005, 46, 218-221.

17. Hinds, W. C. Aerosol Technology. John Wiley \& Sons: New York, 1999; pp 294-302.

18. Maizels, M.; Budde, W. L. A LC/MS method for determination of cyanobacteria toxins in water. Anal. Chem. 2004, 76, 1342-1351.

19. Mark, D.; Vincent, J. H. A new personal sampler for airborne total dust in workplaces. Ann. Occup. Hyg. 1986, 30, 89.

20. McDermott, C. M.; Feola, R.; Plude, J. Detection of cyanobacterial toxins (microcystins) in waters of northeastern Wisconsin by a new immunoassay technique. Toxicon 1995, 33 (11), 14331442.

21. McGovern, J. P.; McElhenney, T. R.; Brown, M. Airborne algae and their allergenicity: Part I air sampling an delineation of the problem. Ann. Allergy 1965, 23, 47-50.

22. Metcalf, J. S.; Bell, S. G.; Codd, G. A. Colorimetric immuno-protein phosphatase inhibition assay for specific detection of microcystins and nodularins of cyanobacteria. Appl. Environ. Microbiol. 2001, 67, 904-909.

23. Mittal, A.; Agarwal, M. K.; Shivpuri, D. N. Studies on allergenic algae of Delhi area: Botanical aspects. Ann. Allergy 1979, 42, 248-252.

24. Monahan, E. C.; Zietlow, C. R. Laboratory comparisons of fresh-water and salt-water whitecaps. J. Geophys. Res. 1969, 74, 6961-6966.

25. Oberholster, P. J.; Botha, A.-M.; Grobbelaar, J. U. Microcystis aeruginosa: source of toxic microcystins in drinking water. African J. Biotech. 2004, 3, 159-168. 
26. Phalen, R. F.; Hinds, W. C.; John, W.; Lioy, P. J.; Lippmann, M.; McCawley, M. A.; Raabe, O. G.; Soderholm, S. C.; Stuart, B. O. Rationale and recommendations for particle size-selective sampling in the workplace. Appl. Ind. Hyg. 1986, 1, 3-12.

27. Philipp, R.; Bates, A. J. Health-risks assessment of dinghy sailing in Avon and exposure to cyanobacteria (Blue-green algae). J. Inst. Water Environ. Manage 1992, 6, 613-617.

28. Pierce, R. H.; Henry, M.; Boggess, S.; Rule, A. Marine toxins in bubble-generated aerosols. In Climate and Health Implications of Bubble-Mediated Sea-Air Exchange, Monahan, E. C., Van Patten, M. A., Eds.; Connecticut Sea Grant College Program: Groton,CT, 1989; pp 27-42.

29. Pierce, R. H.; Henry, M. S.; Blum, P. C.; Lyons, J.; Cheng, Y. S.; Yazzie, D.; Zhou, Y. Brevetoxin concentrations in marine aerosol: human exposure levels during a Karenia brevis harmful algal bloom. Bull. Environ. Contam. 2002.

30. Pilotto, L. S.; Douglas, R. M.; Burch, M. D.; Cameron, S.; Beers, M.; Rouch, G. J.; Robinson, P.; Kirk, M.; Cowie, C. T.; Hardiman, S.; Moore, C.; Attewell, R. G. Health effects of exposure to cyanobacteria (blue-green algae) during recreational water-related activities. Aust. N. Z. J. Public Health 1997, 21, 562-566.

31. Schlichting, H. E. Ejection of microalgae into the air via bursting bubbles. J. Allergy Clinical Immunol. 1974, 53, 185-188.

32. Stewart, I.; Webb, P. M.; Schluter, P. J.; Fleming, L. E.; Burns, J. W. Jr.; Gantat, M.; Backer, L. C.; Shaw, G. R. Epidemiology of recreational exposure to freshwater cyanobacteria- an international prospective cohort study. BMC Public Health 2006, 6, 93-104.

33. Turner, P. C.; Gammie, A. J.; Hollinrake, K.; Codd, G. A. Pneumonia associated with contact with cyanobacteria. Brit. Med. J. 1990, 300, 1440-1441.

34. WHO Guidelines for drinking-water quality, $2^{\text {nd }}$ ed. Addendum to Volume 2. Health criteria and other supporting information; Geneva, World Health Organization: Geneva, 1998.

35. Welker, M.; Khan, S.; Haque, M.M. Islam, S.; Khan, N.H.; Chorus, I.; Fastner, J. Microcystins (cyanobacterial toxins) in surface waters of rural Bangladesh: pilot study. J. Water Health. 2005, 3, 325-337.

36. Woolf, D. K.; Bowyer, P. A.; Monahan, E. C. Discriminating between the film drops and jet drops produced by a simulated white cap. J. Geophys. Res. 1987, 92, 5142-5150.

Samples Availability: Available from the authors.

(C) 2007 by MDPI (http://www.mdpi.org). Reproduction is permitted for noncommercial purposes. 